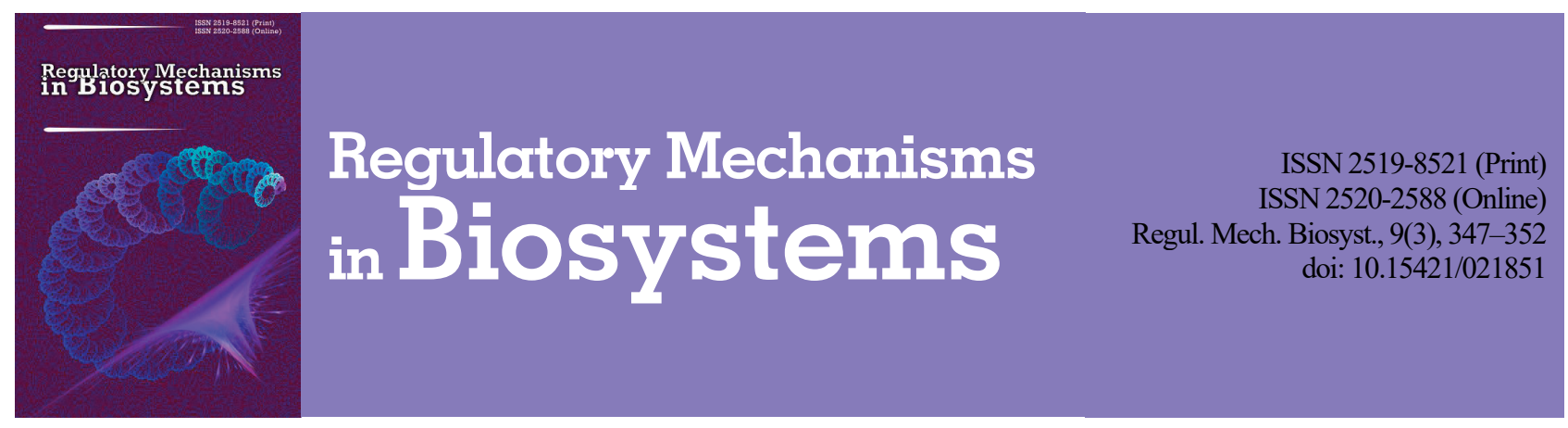

\title{
Effect of photostimulation on biopotentials of maize leaves in conditions of thermal irritation
}

\author{
M. P. Motsnyj, O. V. Elina, N. P. Botsva, S. O. Kochubey \\ Oles Honchar Dnipro National University, Dnipro, Ukraine
}

Article info

Received 02.07.2018

Received in revised form

10.08.2018

Accepted 12.08.2018

Oles Honchar Dnipro National University,

Gagarin ave., 72,

Dnipro, 49010, Ukraine.

Tel.: +38-066-204-32-24.

E-mail:

elina.elena5@gmail.com
Motsnyj, M. P., Elina, O. V., Botsva, N. P., \& Kochubey, S. O. (2018). Effect of photostimulation on biopotentials of maize leaves in conditions of thermal irritation. Regulatory Mechanisms in Biosystems, 9(3), 347-352. doi:10.15421/021851

Plant biopotentials can be used to evaluate their functional state and mechanisms for adaptation to changes in external conditions of their cultivation. The paper is devoted to the experimental study of the dynamics of total potential of maize leaves caused by cold and heat stimuli on the background of photopotential during continuous light stimulation. In the experiments, a specially designed stimulator was used that allowed simultaneous exposure of the plant to light and to thermal irritation. Studies have shown that background continuous light stimulation with white light with a brightness of 250 lux results in an increase in the amplitude of total action potentials caused by rhythmic cold stimulation. The amplitudes of "cold" potentials grew synchronously with the growth of the potential of hyperpolarization under the influence of photostimulation. With the termination of light stimulation, the amplitude of "cold" potentials stabilized. It is assumed that this effect is due to an increase in the amplitude of potentials of action, which correspond to the total potential due to the hyperpolarization of the membranes of the cells that generate them. Such hyperpolarization is due to an increase in the active transport of $\mathrm{H}^{+}$ions through the membrane of cells in the light phase of photosynthesis. It has been shown that during pulsed heat stimulation, the preliminary continuous background light stimulation results in a decrease in the amplitude of "heat" potentials, a reduction in their duration, and the appearance of a short latent hyperpolarization potential in their initial phase. It is established that these changes correlate with the growth of the potential of hyperpolarization caused by background light stimulation. Based on the analysis of the detected changes, it was deduced that an increase in the level of hyperpolarization increases the threshold of excitability of cell membranes generating these potentials. When the photostimulation was switched off, the level of hyperpolarization decreased, but the amplitudes of the "heat" potentials increased. At the same time, the duration of the potentials increased sharply, and the elements characteristic of the variable potentials appeared in them. This may indicate a significant increase in sensitivity to heat irritation with a decrease in the level of hyperpolarization.

Keywords: registration of bioelectric potentials; impulse stimulation; photostimulation; functional state; hyperpolarization, repolarisation.

\section{Introduction}

According to researchers, plant biopotentials can be used to evaluate their functional state (Pjatygin et al., 2008; Vodeneev et al., 2016) and mechanisms for adaptation to changes in external conditions of their cultivation (Pjatygin et al., 2006; Volkov et al., 2013b). Changes in environmental parameters affect the morphological and physiological characteristics of plants and consequently alter their electrical activity (Álvarez \& Sánchez-Blanco, 2015; Gallé et al., 2015; Vuralhan-Eckert et al., 2018). It is also advisable to assess the adaptability of plants to various stress factors such as deficiency and water solubility, ultra high and extremely low temperatures, insufficient light, high radiation, and electrical conductivity (Bendaly et al., 2016; Lyu \& Lazár, 2017). The results of the research show a slowing down of the photosynthesis processes under stress conditions, which together with damage to cell membranes delay the renewal of electrical activity of plants and their normal functioning (Surova et al., 2016).

Over the past decades, a technology has been developed to use modern technical solutions for real-time control and to optimize the influence of external factors on the plants under study. It should also be taken into account that different types of stimulation trigger characteristic electrical signals, each of which has a certain effect on physiological processes (Ríos-Rojas et al., 2014). The use of automated systems for controlling the processes of external exposure to plants (Chernetchenko et al., 2013; Zheng et al., 2015) and quantitative assessment of existing factors with various irritations (Das et al., 2016; Berk et al., 2016; Wijewardana et al., 2016) are very important in understanding the processes of biogenesis of plants.

In today's conditions, the task of finding effective scientific methods for increasing the productivity of agricultural crops is relevant. In this sense, the study of biopotentials caused by light, in particular continuous, stimulation is useful (Trebacz \& Sievers, 1998; Chernetchenko et al., 2015). It is also important to use simultaneously other stimuli, such as temperature, including impulse stimulation (Volkov et al., 2013a; Zhou et al., 2014; Tao et al., 2016). Metabolic acclimatization of plants to heat or cold stress affects their development and livelihoods. At the same time, high temperature stress prevents the increase of crop yields, therefore, an understanding of the physiological processes which under adverse temperature conditions negatively affects photosynthesis is important (Lyu \& Lazár, 2017; Tao et al., 2016). Adequate stimulation allows for both temperature and light irritation.

Temperature stimulation is convenient for use during experiments; because using thermoelements based on the Peltier effect can be applied to plant tissues dosed with thermostimulants. The duration of these thermostimulants $\Delta \mathrm{T}$ is determined by the duration of the current pulse through the thermocouple, the change in temperature $\Delta \mathrm{t}\left({ }^{\circ} \mathrm{C}\right)$ - the magnitude of the current in the pulse. The temperature difference is measured by a miniature differential thermocouple.

The application of the described thermostimulation method allows one to change the modulus of the thermo pulse. To do this, it is enough 
to change the direction of current through the thermocouple with a simple mechanical switch.

Thermostimulation can be of two types: dose reduction or increase in temperature. In practice, lower temperatures are more often used as less traumatic, because at elevated temperatures, even in a zone of intact temperatures, potentials of action with obvious signs of variable potential are often generated. Temperature stimuli act directly on plasmolma cells, causing changes in its permeability.

Cooling depolarizes the cell membrane, reduces its potential to a threshold level, which leads to the potential of action, while heating in the physiological range increases the membrane potential. The emergence of the action potential occurs when the physiological range is already overheated, and, apparently, is associated with the development of the initial reversal phase of thermal damage. Sometimes, the potential for action in the case of heating occurs also in the physiological range of temperatures, but not at elevated temperatures, and when the temperature decreases to the initial level when the thermometer is switched off, the stimulator. This is most strongly manifested when the current is turned on.

Light stimulation is also adequate, but unlike thermal, the change in leaf illumination does not produce potential for action and is not a reflection of electrical processes in chloroplasts under photosynthesis (Szechyńska-Hebda \& Karpiński, 2013; Hasegawa et al., 2016). The stimulation during experiments is quite easy to ask and control its parameters with the help of a luxmetre. As a light source, a light-emitting diode is used which emits light of a known fixed wavelength. Duration of the stimulus $\Delta \mathrm{T}$ is given by the duration of the current pulse through the light-emitting diode, and the source illumination of the photodiode is the magnitude of the current through it.

The purpose of the work presented here is to study the dynamics of total potential of maize leaves caused by cold and heat stimuli on the background of photopotential during continuous light stimulation.

\section{Materials and methods}

Research on biopotentials was carried out on well-developed and prepared maize sprouts (type Spirit H7). The selected maize corn was sown in special containers filled with soil and sprouted in a humid environment. Seedlings were used in experiments in 20-25 days after the emergence of shoots. Experiments were carried out on a universal automated system for the study of plant biopotentials (Fig. 1).

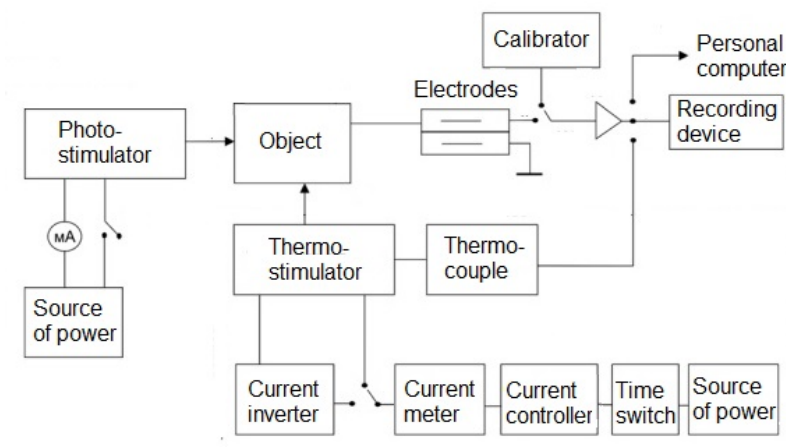

Fig. 1. Block diagram of universal automated system for the study of plant biopotentials

The seedlings in a container with soil were placed in a shielded thermostatted chamber in which a stable temperature of $20{ }^{\circ} \mathrm{C}$ was maintained. In the experiment, a special universal stimulator was used, which allowed simultaneously creation of both temperature and light irritating stimuli. To do this, the device for fixing the sheet on the thermostimulator was fitted with a miniature light-emitting diode with a special infrared filter to eliminate the heating of the sheet with an lightemitting diode.

The maize sheet was fixed on the stimulator and non-polarized electrodes applied (EVL-1m). The active electrode was located on the active surface of the thermostimulator and the light-emitting diode of the photostimulator. Thus, the active zone of potential output could simultaneously be subjected to two types of stimulation - continuous light and pulsed thermal. The indifferent electrode is located on the sheet over the stimulation zone. The outputs of the electrodes were connected to the input of the previous amplifier. The signal from its output was fed to the terminals of the Endim recorder and the digitizing device for data processing on the personal computer.

The experimental method was to use dosed pulsed thermal stimuli against the background of light stimulation. Thermopotentials were called with a thermostimulator, and the duration and frequency of thermostimulation were set using a time relay. This thermostimulation method allows one to change the modulus of thermocouples. The required temperature was regulated by the current value via a thermostimulator, which was measured by a digital ammeter. The temperature on the working surface of the thermostimulator was measured using a miniature differential thermocouple.

For light stimulation, a white light with a brightness of 250 lux was used. Amplitude calibration was calibrated by a generator.

\section{Results}

In the first series of experiments, changes in the potential of maize leaves caused by rhythmic cold irritations with frequency $\mathrm{f}=1 / 15 \mathrm{~Hz}$ were studied. Cold stimuli were used with a temperature difference $\Delta t=$ $-6{ }^{\circ} \mathrm{C}$ duration of 5 seconds. A typical result from this series of experiments is shown in Figure 2.

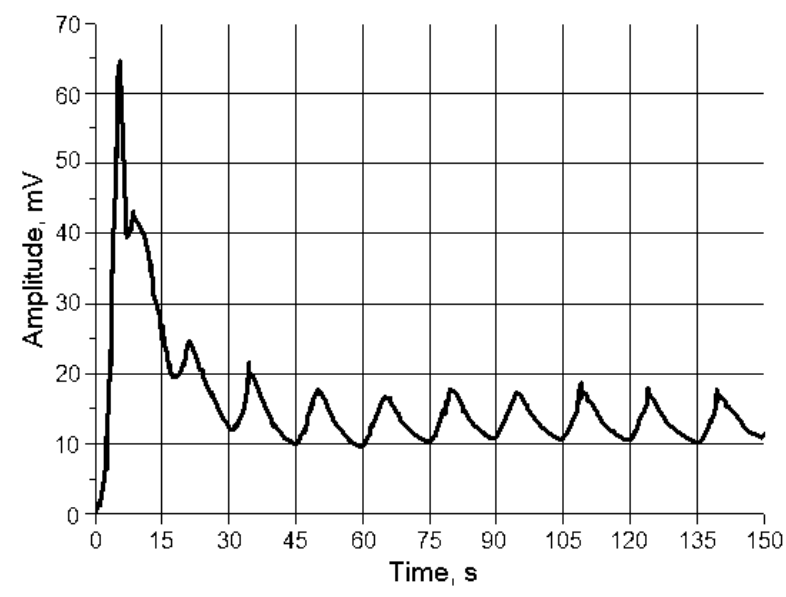

Fig. 2. Potentials of maize leaves at rhythmic stimulation (frequency $\mathrm{f}=1 / 15 \mathrm{~Hz}$ ) with cold impulses duration of 5 seconds with temperature difference $\Delta t=-6{ }^{\circ} \mathrm{C}$

From Figure 2 it is evident that with this variant of irritation on the maize leaf, action potentials are recorded, the amplitude of which in the interval of 5 to 45 seconds after the start of stimulation drops sharply from 65 to $18 \mathrm{mV}$ and at the 45th second stabilizes at this level.

According to the results of 12 such experiments, the dependence of the amplitude of the "cold" potential on the time between the first and the next cold impulses is obtained (Fig. 3). To reveal general patterns of potential dynamics at different absolute values of amplitudes during construction of this graph, the amplitudes of the potentials were expressed as a percentage of the amplitude of the first response. Based on the results obtained, it is evident that over a period of about 60 seconds, the average response amplitude for rhythmic cold stimuli drops sharply, and then stabilizes at $20 \%$ of the amplitude of the first response.

In the second series of experiments for stimulating maize leaves, heat stimuli were used with a temperature difference $\Delta t=7{ }^{\circ} \mathrm{C}$ duration of 5 seconds and two frequencies $\mathrm{f}_{1}=1 / 15 \mathrm{~Hz}$ and $\mathrm{f}_{2}=1 / 30 \mathrm{~Hz}$. Typical results from this series of experiments are shown in Figure 4 and 5, respectively. In the case of heat stimulation, two-phase potentials that have a phase of hyperpolarization and a phase of depolarization are recorded. Figure 4 shows that under conditions of stimulation with frequency $f_{1}=$ $1 / 15 \mathrm{~Hz}$, the phase of hyperpolarization has a maximum of $14 \mathrm{mV}$ at the 5th second, then the potential level passes through zero to the phase of depolarization, which remains until the appearance of the next stimulus. 


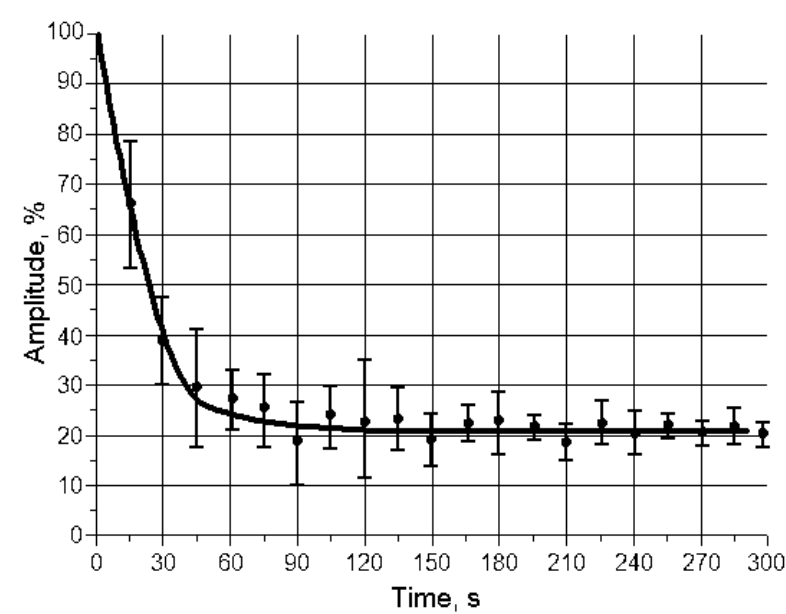

Fig. 3. Dynamics of relative "cold" potential of maize leaves depending on the time between the first and subsequent stimuli (frequency of stimuli $\mathrm{f}=1 / 15 \mathrm{~Hz}$ ): vertical lines indicate reliable intervals for the average, calculated with a reliability of 0.85

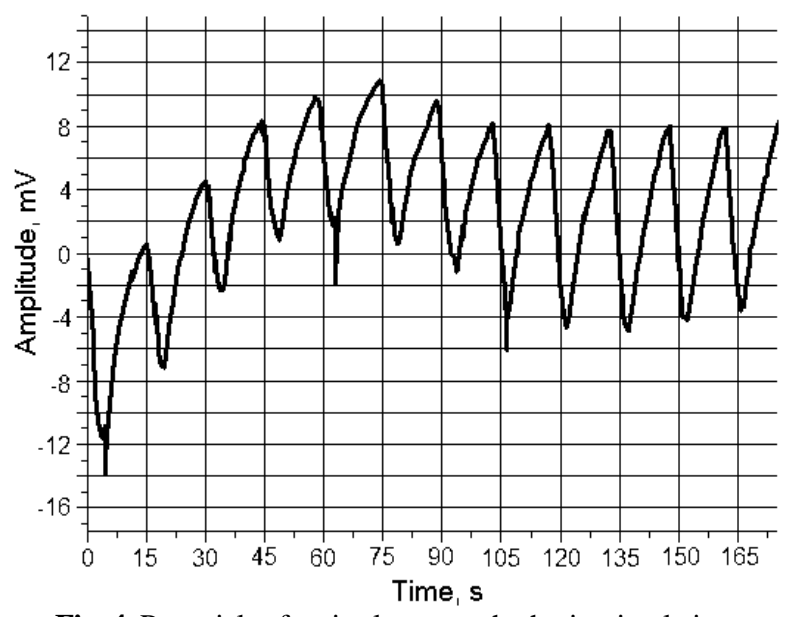

Fig. 4. Potentials of maize leaves at rhythmic stimulation (frequency $\mathrm{f}_{1}=1 / 15 \mathrm{~Hz}$ ) with heat impulses duration of 5 seconds with temperature difference $\Delta \mathrm{t}=7^{\circ} \mathrm{C}$

In Figure 5 it is evident that under conditions of stimulation with frequency $\mathrm{f}_{2}=1 / 30 \mathrm{~Hz}$, the phase of hyperpolarization has a maximum of $10 \mathrm{mV}$. The level of potential reaches zero faster than with stimulateon with frequency $f_{1}=1 / 15 \mathrm{~Hz}$. At the 15th second the amplitude of the depolarization is $4 \mathrm{mV}$. Potential is stabilized at this level until the next stimulus is irritating.

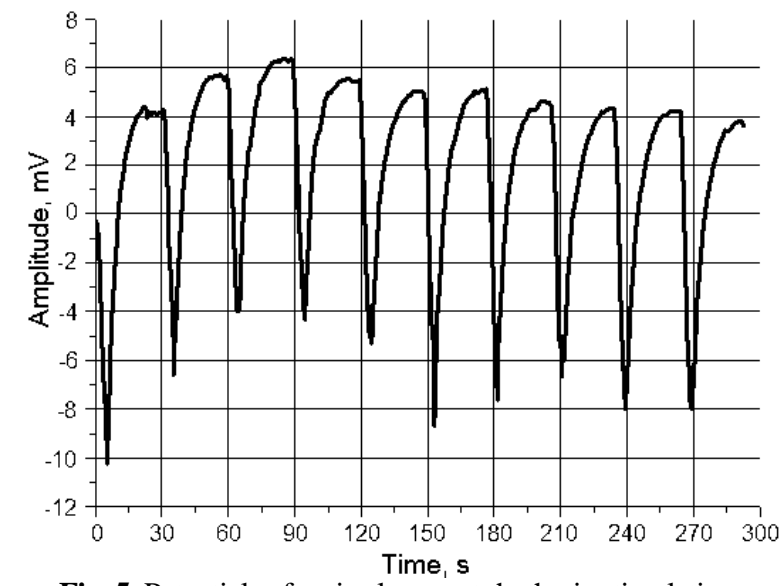

Fig. 5. Potentials of maize leaves at rhythmic stimulation (frequency $\mathrm{f}_{2}=1 / 30 \mathrm{~Hz}$ ) with heat impulses duration of 5 seconds with temperature difference $\Delta t=7{ }^{\circ} \mathrm{C}$

According to the results of 8 similar experiments with the frequency of stimulation $\mathrm{f}_{1}=1 / 15 \mathrm{~Hz}$ and 7 experiments with frequency $\mathrm{f}_{2}=$
$1 / 30 \mathrm{~Hz}$, the dependences of the relative amplitude of the "heat" potential on the time between the first and subsequent stimulations of heat stimulation were obtained (Fig. 6, 7). The amplitudes of potentials, as in the previous series, were calculated as a percentage of the amplitude of the first response.

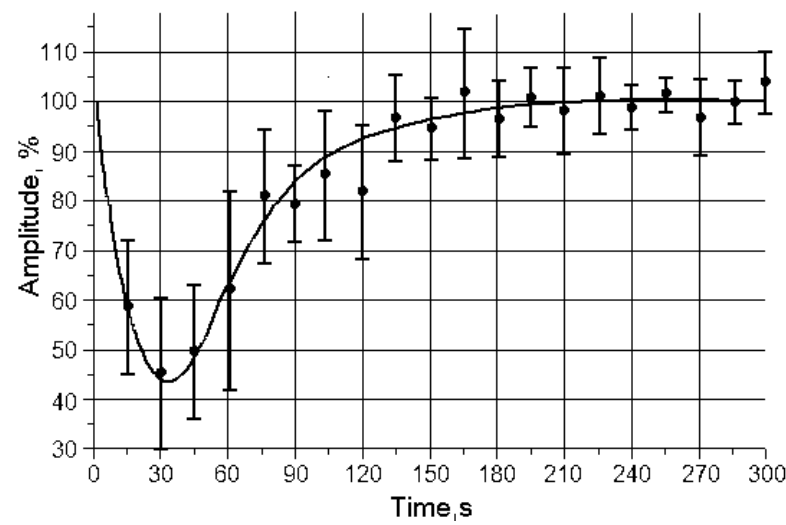

Fig. 6. Dynamics of relative "heat" potential of maize leaves depending on the time between the first and subsequent stimuli (frequency of stimuli $\mathrm{f}_{1}=1 / 15 \mathrm{~Hz}$ ): vertical lines indicate reliable intervals for the average, calculated with a reliability of 0.85

The dynamics of "heat" potentials at the frequency of heat stimuli $\mathrm{f}_{1}=$ $1 / 15 \mathrm{~Hz}$ is such that the response amplitude after a certain decrease during the first 30 seconds increases again and after 180 seconds stabilizes at the initial level.

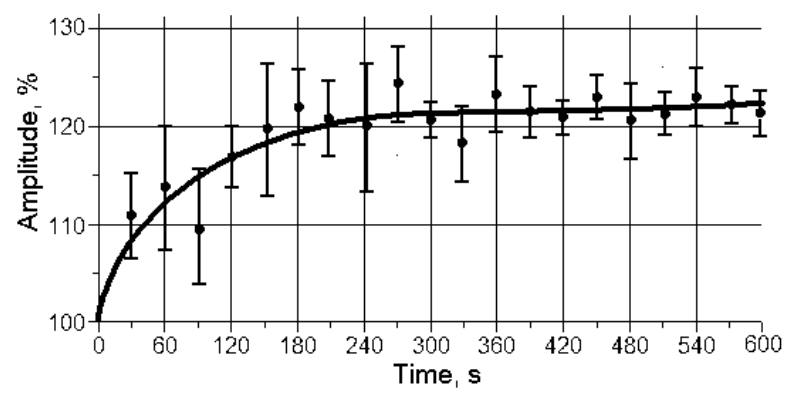

Fig. 7. Dynamics of relative "heat" potential of maize leaves depending on the time between the first and subsequent stimuli (frequency of stimuli $\mathrm{f}_{2}=1 / 30 \mathrm{~Hz}$ ): vertical lines indicate reliable intervals for the average, calculated with a reliability of 0.85

At the frequency of heat stimuli $\mathrm{f}_{2}=1 / 30 \mathrm{~Hz}$, the amplitude of the potentials in 180 seconds stabilizes at $120 \%$, and then even more with respect to the amplitude of the first response.

In the next series of experiments, the interaction of the potential caused by the continuous illumination of the sheet with white light with a brightness of 250 lux, with potentials caused by rhythmic cold stimulation with a temperature difference $\Delta \mathrm{t}=-5{ }^{\circ} \mathrm{C}$ and duration of $5 \mathrm{se}-$ conds was investigated. The rate of decrease of temperature $-1{ }^{\circ} \mathrm{C} / \mathrm{s}$. During the experiment, a recorder was started at a speed of $50 \mathrm{~cm} / \mathrm{s}$, a photostimulator was turned on, and then cold spots were applied to the sheet at an interval of 60 seconds. One of the typical results of this series of experiments is shown in Figure 8. It is evident that light stimulation leads to the development of a slow photopotential of hyperpolarization, on the background of which are recorded the total potentials of action caused by cold irritation.

On the basis of the obtained data, a plot of the dependence of the amplitude of "cold" potentials on time was constructed (Fig. 9). The duration of the potentials was 30 seconds, the amplitude depends on the time that elapses from the beginning of stimulation to the moment of registration. The analysis of the results shows that the first "cold" response was registered at the background of hyperpolarization at $+1.6 \mathrm{mV}$ and is $-3.3 \mathrm{mV}$. The second, caused by the stimulus in 60 seconds, has a minimum amplitude of $-2 \mathrm{mV}$ and is recorded at a hyperpolarization 
level of $+3 \mathrm{mV}$. With increasing hyperpolarization, the amplitude of the potentials increases and at the moment of switching off the photostimulator (600 seconds) the level of hyperpolarization is $+6 \mathrm{mV}$, and the amplitude of the "cold" biopotential reaches $-4 \mathrm{mV}$. From this it follows that an increase in the level of hyperpolarization leads to an increase in the amplitude of "cold" potentials.

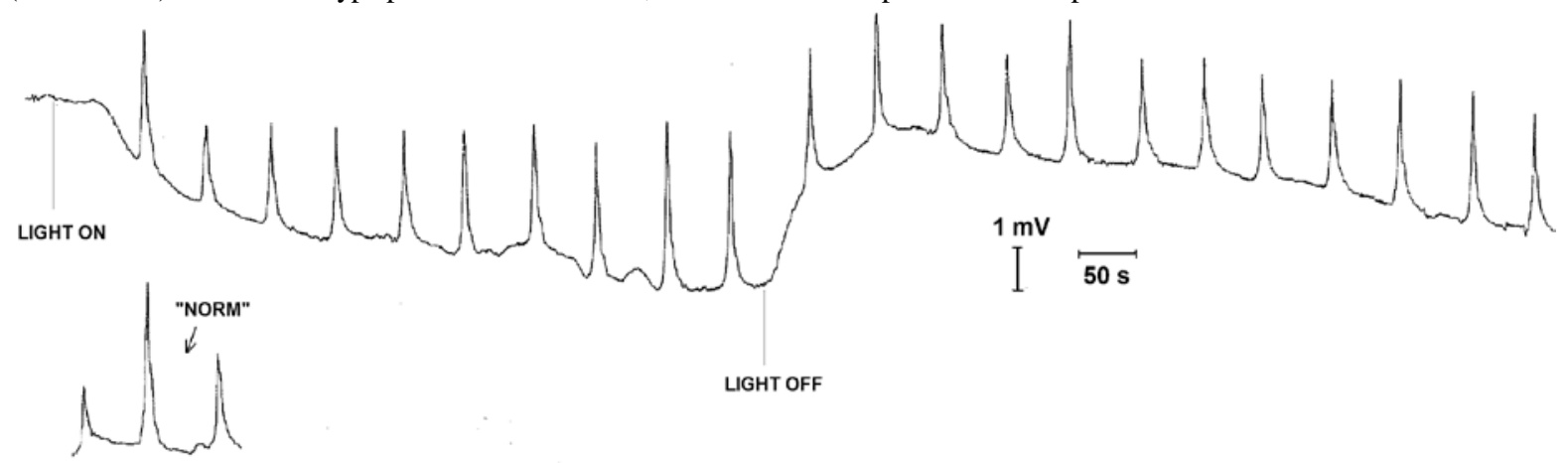

Fig. 8. Dynamics of the amplitude of "cold" potentials caused by rhythmic cold irritations $\Delta \mathrm{t}=-5{ }^{\circ} \mathrm{C}$ duration 5 seconds against the background of photopotential with continuous light stimulation with white light with illumination of 250 lux

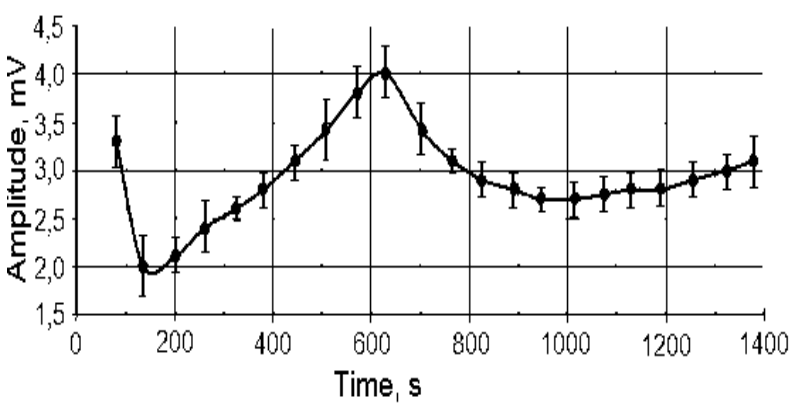

Fig. 9. The dynamics of "cold" potentials of maize leaves depending on the time between the first and subsequent cold stimuli with continuous light stimulation: vertical lines indicate reliable intervals for the average, calculated with a reliability of 0.85
After turning off the photostimulant, a sharp repolarization of the membrane from the level $+6 \mathrm{mV}$ to $+3 \mathrm{mV}$ was observed. The amplitude of the first recorded after this response is $-3.5 \mathrm{mV}$, and when the level of hyperpolarization reaches a minimum of $+1 \mathrm{mV}$, the amplitude of the response is $-3 \mathrm{mV}$. Starting from the 750th second after the start of stimulation, there is a second wave of increasing hyperpolarization. At the same time, the amplitude of responses increases.

In the next series of experiments, on the background of continuous photostimulation, heat stimulation was used. To do this, the direction of the current was changed through the thermostimulator. The results of one of the typical experiments of this series are shown in Figure 10. From Figure 10 it is evident that at the beginning of photostimulation there is a depolarization phase with a duration of 100 seconds with a maximum of $-7 \mathrm{mV}$ at the 70th second, followed by a phase of hyperpolarization. The first response is the potential of depolarization with a duration of 20 seconds with an amplitude of $-3 \mathrm{mV}$ against a background of $+1 \mathrm{mV}$ hyperpolarization.

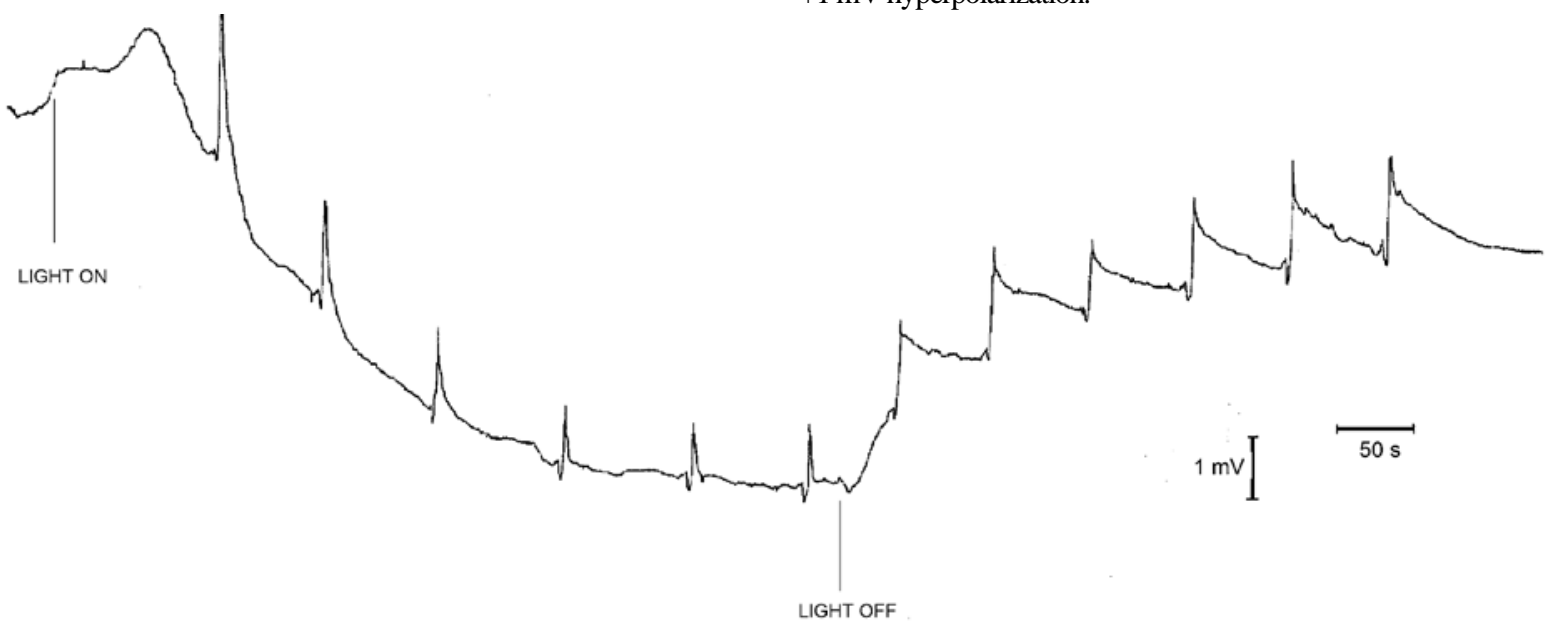

Fig. 10. Dynamics of potentials caused by rhythmic heat stimulation $\Delta \mathrm{t}=+6.5^{\circ} \mathrm{C}$ duration 5 seconds, on the background of photopotential with continuous light stimulation with white light with illumination of 250 lux

On the basis of the obtained data, a plot of the dependence of the amplitude of the "heat" potentials on time was constructed (Fig. 11).

With further heat stimuli, the level of hyperpolarization increases, and the potential amplitude decreases. Then, at the 300th second, hyperpolarization stabilizes at $+8.5 \mathrm{mV}$, and the potential amplitude is $-1.2 \mathrm{mV}$. Note that this significantly reduces the duration of the potential up to 10 seconds. After turning off the photostimulator at 500 seconds, rapid repolarization is observed. The first response of the "heat" potential after turning off of the photostimulator (at 560th second) occurs at the background of hyperpolarization at $+7 \mathrm{mV}$ and has an amplitude of $-1.5 \mathrm{mV}$. Over time, hyperpolarization decreases, and the potential amplitude increases. By the end of the registration, the level of hyperpolarization is $+3 \mathrm{mV}$, and the amplitude of the potential is $-2 \mathrm{mV}$, respectively.
Note that after turning off the photostimulator in the phase of repolarization, the shape of the potentials changes substantially, their duration is significantly increases (more than 60 seconds) and characteristic features of the variational potential appear.

\section{Discussion}

It is known that in the absence of background photostimulation, in particular under these conditions, the first series of experiments were carried out, stabilization of the potential amplitude was observed over time (Pjatygin et al., 2008; Motsnyj et al., 2017). The essence of the stabilization is that the next response falls into the phase of the relative refractoriness of the previous recall. In the presence of continuous light 
stimulation, the picture changes substantially, as the background potential causes hyperpolarization of the membrane by increasing the active transport of $\mathrm{H}^{+}$ions that occurs during the light phase of photosynthesis. The transformation of energy caused by the active transport of ions is due to the change in the electrical potentials of the membrane of the plant cell (Pjatygin et al., 2008). The obtained results give grounds to assert that the hyperpolarization of the illuminated part of the sheet that was in contact with the active electrode causes the growth of the metabolic component of the membrane potential of the cell against the background of light stimulation. This component is related to the activity of the proton $\mathrm{H}^{+}$pump. The total flow of $\mathrm{H}^{+}$ions from the intercellular medium to the middle of the cell may be due to the depolarization of the cell caused by the action of light (Pjatygin et al., 2006; Hasegawa et al., 2016; Lyu \& Lazár, 2017).

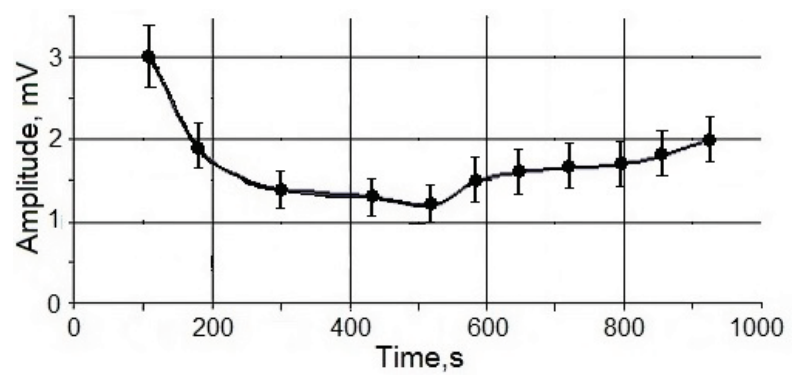

Fig. 11. Dynamics of "heat" potentials of maize leaves depending on the time between the first and subsequent thermal stimuli with continuous light stimulation: vertical lines indicate reliable intervals for the average, calculated with a reliability of 0.85

The results of experiments, however, do not exclude the possibility of absorption of light by chloroplasts, which leads to the activation of zones in plasmolma ion channels penetrating to protons, and can cause a change in $\mathrm{pH}$ on the cell surface (Vodeneev et al., 2012).

As is known, increasing the membrane potential leads to an increase in the amplitude of the potential of the action of individual cells, which form the "cold" potential recorded in these experiments (Volkov et al., 2013a). That is why with the increase in the level of hyperpolarization caused by background light stimulation, the total cell potential is also increased due to cold irritation (Álvarez \& Sánchez-Blanco, 2015). After turning off the photostimulator, rapid repolarization is observed, which is associated with the inactivation of the active transport of $\mathrm{H}^{+}$ ions, which leads to a decrease in the registered potentials. This assumption is confirmed by the fact that under the action of the second wave of hyperpolarization (after turning off the photostimulator) the amplitude of the potentials increases again (Pjatygin et al., 2006; Pjatygin et al., 2008).

From the analysis of the data obtained in the last series of experiments, it follows that when using thermal stimuli on the background of light stimulation, the parameters of the obtained potentials are significantly dependent on the temperature difference $\Delta \mathrm{t}\left({ }^{\circ} \mathrm{C}\right)$.

At $\Delta \mathrm{t}=+5.0^{\circ} \mathrm{C}$ there is a potential, with the parameter similar to "cold", and at $\Delta \mathrm{t}=+7.0^{\circ} \mathrm{C}$ the potential has signs of the variable potential. In our experiments, $\Delta \mathrm{t}=+6.5^{\circ} \mathrm{C}$ is used. As we see from Figure 10, when the photostimulator is turned on, pulses are recorded, with parameters similar to "cold", and when the photostimulator is turned off, in the phase of the repolarization, the pulse parameters are similar to the parameters of the variable potentials. This suggests that in the phase of repolarization the cells' sensitivity to thermal irritation is significantly increased.

Hyperpolarization of the membranes leads to the reverse effect. Reducing the amplitude of "thermal" potentials may be due to the fact that the hyperpolarization of membranes leads to an increase in the excitatory threshold of cells that generate the potential of action. As a result, the total amplitude of the potential decreases. In support of this assumption, the decrease in the duration of registered potentials is indicated. We note that with increasing hyperpolarization in the light phase, the amplitude and duration of the positive jump increases in front of the "thermal" potential. This confirms the hypothesis that the potential effect does not occur if the part of the plant's leaf is heated, and when the thermostimulator is turned off, which is consistent with the literature data (Vodeneev et al., 2012).

Thus, the results of the experiments support the existing view that plant cell responses to different physical stimuli are combined (Vuralhan-Eckert et al., 2018) and indicate that maize leaves can process at least two simultaneously applied stimuli.

\section{Conclusions}

Studies have shown that background light continuous stimulation leads to an increase in the amplitude of the total action potentials caused by rhythmic cold stimulation. The increase in the amplitude of these potentials occurs synchronously with the growth of the hyperpolarization potential, caused by photostimulation. When the photostimulator is turned off, the amplitude of the potentials is stabilized. This effect may be associated with an increase in the amplitude of potentials due to hyperpolarization of cell membranes. The indicated hyperpolarization can be caused by continuous light stimulation due increasing the active transport of $\mathrm{H}^{+}$protons in the light phase of photosynthesis.

During pulsed heat stimulation the background continuous light stimulation results in a decrease in the amplitude of "heat" potentials, a significant reduction in their duration, and the appearance in the initial phase of the short-acting potential of hyperpolarization. The experiments have shown that these changes correlate with the growth of the potential of hyperpolarization, caused by photostimulation.

All of the changes described may indicate that an increase in the level of hyperpolarization leads to an increase in the threshold of excitability of cell membranes, generating these potentials. When the photostimulator is turned off, the level of hyperpolarization decreases and the potential amplitude increases. The duration of potentials in which elements of variable potentials appear also increase. This may be a sign of a significant increase in sensitivity to heat irritation with a decrease in the level of hyperpolarization.

\section{References}

Álvarez, S., \& Sánchez-Blanco, M. J. (2015). Comparison of individual and combined effects of salinity and deficit irrigation on physiological, nutritional and ornamental aspects of tolerance in Callistemon laevis plants. Journal of Plant Physiology, 185, 65-74.

Bendaly, A., Messedi, D., Smaoui, A., Ksouri, R., Bouchereau, A., \& Abdelly, C. (2016). Physiological and leaf metabolome changes in the xerohalophyte species Atriplex halimus induced by salinity. Plant Physiology and Biochemistry, 103, 208-218.

Berk, P., Hocevar, M., Stajnko, D., \& Belsak, A. (2016). Development of alternative plant protection product application techniques in orchards, based on measurement sensing systems: A review. Computers and Electronics in Agriculture, 124, 273-288.

Chernetchenko, D. V., Motsnyj, M. P., Botsva, N. P., Elina, O. V., \& Milykh, M. M. (2013). Avtomitizovana systema reestraciy bioelectrichnih potencialiv [Automated experiment for bioelectrical potentials registration]. Visnyk of Dnipropetrovsk University. Biology, Ecology, 21(2), 70-75 (in Ukrainian).

Chernetchenko, D. V., Motsnyj, M. P., Botsva, N. P., \& Elina, O. V. (2015). Doslidzhennja fotoindukovanyh potencialiv lystja percju [Research of photoinduced potentials of pepper leaves]. Visnyk of Dnipropetrovsk University. Biology, Ecology, 23(2), 225-229 (in Ukrainian).

Das, S., Ajiwibawa, B. J., Chatterjee, S. K., Ghosh, S., Maharatna, K., Dasmahapatra, S., Vitaletti, A., Masi, E., \& Mancuso, S. (2015). Drift removal in plant electrical signals via IIR filtering using wavelet energy. Computers and Electronics in Agriculture, 118, 15-23.

Gallé, A., Lautner, S., Flexas, J., \& Fromm, J. (2015). Environmental stimuli and physiological responses: The current view on electrical signalling. Environmental and Experimental Botany, 114, 15-21.

Hasegawa, Y., Murohashi, F., \& Uchida, H. (2016). Plant physiological activity sensing by bioelectric potential measurement. Procedia Engineering, 168, 630-633.

Lyu, H., \& Lazár, D. (2017). Modeling the light-induced electric potential differrence $(\Delta \Psi)$, the $\mathrm{pH}$ difference $(\Delta \mathrm{pH})$ and the proton motive force across the thylakoid membrane in $\mathrm{C}_{3}$ leaves. Journal of Theoretical Biology, 413, 11-23.

Motsnyj, M. P., Botsva, N. P., Elina, O. V., Chernetchenko, D. V., Sadovskaya, L. Y., \& Tykhomyrov, O. Y. (2017). Effect of external lighting on biopotential of maize leaves caused by pulsed temperature stimulation. Regulatory Mechanisms in Biosystems, 8(2), 179-184. 
Pjatygin, S. S., Vodeneev, V. A., \& Opritov, V. A. (2006). Depoljarizacija plazmaticheskoj membrany kak universal'naja pervichnaja biojelektricheskaja reakcija rastitel'nyh kletok na dejstvie razlichnyh faktorov [Depolarization of the plasma membrane as a universal primary bioelectric reaction of plant cells to the action of various factors]. Uspehi Sovremennoj Biologii, 126(5), 492-502 (in Russian).

Pjatygin, S. S., Opritov, V. A., \& Vodeneev, V. A. (2008). Signal'naja rol' potenciala dejstvija u vysshih rastenij [Signal role of the action potential in higher plants]. Fiziologija Rastenij, 55, 312-319 (in Russian).

Ríos-Rojas, L., Tapia, F., \& Gurovich, L. A. (2014). Electrophysiological assessment of water stress in fruit-bearing woody plants. Journal of Plant Physiology, 171(10), 799-806.

Surova, L., Sherstneva, O., Vodeneev, V., Katicheva, L., Semina, M., \& Sukhov, V. (2016). Variation potential-induced photosynthetic and respiratory changes increase ATP content in pea leaves. Journal of Plant Physiology, 202, 57-64.

Szechyńska-Hebda, M., \& Karpiński, S. (2013). Light intensity-dependent retrograde signalling in higher plants. Journal of Plant Physiology, 170(17), 1501-1516.

Tao, Z., Chen, Y., Li, C., Zou, J., Yan, P., Yuan, S., Wu, X., \& Sui, P. (2016). The causes and impacts for heat stress in spring maize during grain filling in the North China Plain - A review. Journal of Integrative Agriculture, 15(12), 2677-2687.

Trebacz, K., \& Sievers, A. (1998). Action potentials evoked by light in traps of Dionaea muscipula Ellis. Plant Cell Physiology, 39, 369-372.
Vodeneev, V. A., Katicheva, L. A., \& Sukhov, V. S. (2016). Electrical signals in higher plants: Mechanisms of generation and propagation. Biophysics, 61, 505-512.

Vodeneev, V., Orlova, A., Morozova, E., Orlova, L., Akinchits, E., Orlova, O., \& Sukhov, V. (2012). The mechanism of propagation of variation potentials in wheat leaves. Journal of Plant Physiology, 169(10), 949-954.

Volkov, A. G., O’Neal, L., Volkova, M. I., \& Markin, V. S. (2013a). Morphing structures and signal transduction in Mimosa pudica L. induced by localized thermal stress. Journal of Plant Physiology, 170(15), 1317-1327.

Volkov, A. G., Vilfranc, C. L., Murphy, V. A., Mitchell, C. M., Volkova, M. I., O’Neal, L., \& Markin, V. S. (2013b). Electrotonic and action potentials in the Venus flytrap. Journal of Plant Physiology, 170(9), 838-846.

Vuralhan-Eckert, J., Lautner, S., \& Fromm, J. (2018). Effect of simultaneously induced environmental stimuli on electrical signalling and gas exchange in maize plants. Journal of Plant Physiology, 223, 32-36.

Wijewardana, C., Henry, W. B., Gao, W., \& Reddy, K. R. (2016). Interactive effects on $\mathrm{CO}_{2}$, drought, and ultraviolet-B radiation on maize growth and development. Journal of Photochemistry and Photobiology B: Biology, 160, 198-209.

Zheng, L., Wang, Z., Sun, H., Zhang, M., \& Li, M. (2015). Real-time evaluation of corn leaf water content based on the electrical property of leaf. Computers and Electronics in Agriculture, 112, 102-109.

Zhou, H., Sun, Y., Cheng, Q., Schulze Lammers, P., Damerow, L., Schumann, H., Norton, T., \& Wen, B. (2014). In situ observation of thermal and hydraulic responses of sunflower stem to cold water irrigation using embedded thermocouples. Computers and Electronics in Agriculture, 109, 195-199. 